\title{
Stability and Performance Investigations of Model Predictive Controlled Active-Front-End (AFE) Rectifiers for Energy Storage Systems
}

\author{
Md. Parvez Akter ${ }^{*}$, Saad Mekhilef ${ }^{\dagger}$, Nadia Mei Lin Tan ${ }^{* *}$, and Hirofumi Akagi*** \\ ${ }^{*}$ Power Electronics and Renewable Energy Research Laboratory (PEARL), Dept. of Electrical Engineering, \\ University of Malaya, Kuala Lumpur, Malaysia \\ ${ }^{* *}$ Dept. of Electrical Power Engineering, Universiti Tenaga Nasional, Kajang, Malaysia \\ ${ }^{* * *}$ Dept. of Electrical and Electronic Engineering, Tokyo Institute of Technology, Tokyo, Japan
}

\begin{abstract}
This paper investigates the stability and performance of model predictive controlled active-front-end (AFE) rectifiers for energy storage systems, which has been increasingly applied in power distribution sectors and in renewable energy sources to ensure an uninterruptable power supply. The model predictive control (MPC) algorithm utilizes the discrete behavior of power converters to determine appropriate switching states by defining a cost function. The stability of the MPC algorithm is analyzed with the discrete z-domain response and the nonlinear simulation model. The results confirms that the control method of the active-front-end (AFE) rectifier is stable, and that is operates with an infinite gain margin and a very fast dynamic response. Moreover, the performance of the MPC controlled AFE rectifier is verified with a $3.0 \mathrm{~kW}$ experimental system. This shows that the MPC controlled AFE rectifier operates with a unity power factor, an acceptable THD (4.0 \%) level for the input current and a very low DC voltage ripple. Finally, an efficiency comparison is performed between the MPC and the VOC-based PWM controllers for AFE rectifiers. This comparison demonstrates the effectiveness of the MPC controller.
\end{abstract}

Key words: AC-DC power conversion, Active-Front-End (AFE) rectifier, Energy storage system, Model Predictive Control (MPC), Stability analysis

\section{INTRODUCTION}

Energy storage systems have been employed in utility and transportation applications as well as in renewable energy sources to ensure power reliability, active power control, load leveling and frequency control [1]-[3]. Generally, energy storage systems use static storage devices such as electric double layer capacitors, Li-ion batteries, lead-acid batteries and nickel metal-hydride batteries [4]. These static storage devices contain a high power and energy density but require proper operation such as low ripple current and voltage at the a DC side.

Manuscript received Jun. 3, 2014; accepted Aug. 26, 2014

Recommended for publication by Associate Editor Jun-Keun Ji.

${ }^{\dagger}$ Corresponding Author: saad@um.edu.my

Tel: +603 7967 6851, Fax: +603 7967 5316, University of Malaya

*PEARL, Dept. of Electrical Eng., University of Malaya, Malaysia

** Dept. of Electrical Power Eng., Universiti Tenaga Nasional, Malaysia

${ }^{* * *}$ Dept. of Electrical and Electronic Eng., Tokyo Inst. of Tech., Japan
The active front end (AFE) rectifier is an essential part of energy storage systems due to its bidirectional-power-flow, grid synchronization and DC power management capabilities [5]. The control algorithm of the AFE rectifier should be highly stable and efficient since it needs to prevent the problems of poor power quality due to high total harmonic distortion (THD), low power factor, ac voltage distortion, and ripples in the DC current and voltage [6]-[8]. Therefore, several control methods have been investigated to improve the efficiency and performance of the AFE rectifier. The classical control of the AFE rectifier is generally based on a voltage-oriented control (VOC) scheme, which decomposes the active and reactive power into stationary $\alpha-\beta$ coordinates and synchronizes the powers with the rotating $d-q$ reference frames by characterizing the current control loops by using PI controllers [9], [10]. Moreover, a virtual-flux-oriented control has been proposed in [11], which also uses PI controllers. The major limitation of these control schemes is the need for 


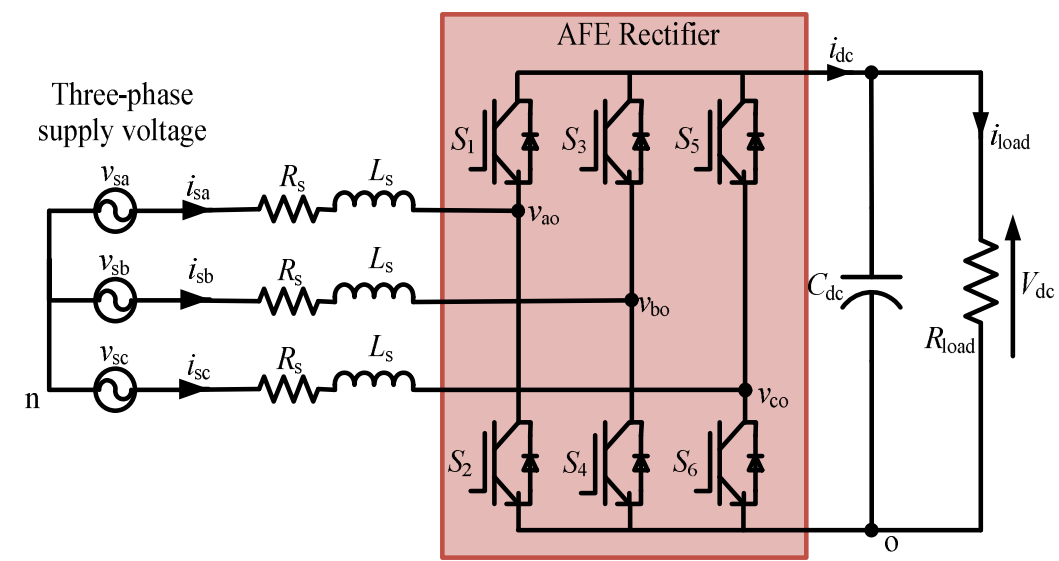

Fig. 1. Active front end rectifier topology.

tuning the PI controllers that further affects the co-ordinate transform accuracy. Furthermore, direct power control (DPC) schemes [12], [13] that have been applied based on the direct torque control (DTC) [14]-[16] principle also use PI controllers. In order to improve the performance of converters, look-up table (LUT) based direct power control (DPC) schemes have been proposed in [17], [18], in which the switching action of the converter is done with a predefined switching state table on the basis of the active and reactive power characteristics. The look-up table based DPC methods have a variable switching frequency problem, which produces undesirable harmonic spectrums. To overcome this variable switching, a fuzzy-logic based switching state selection criteria has been presented in [19], [20] to avoid the predefined switching table. Although the active and reactive powers are smoothed in the fuzzy-logic based DPC algorithm when compared with the classical DPC, its sampling frequency is high. Therefore, a sliding mode nonlinear control approach has been investigated in [21] for active and reactive power regulation of grid connected DC-AC converters, which is very much dependent on control variables.

The principle feature of the model predictive control (MPC) scheme is to predict the future behavior of the control variables and it has become an attractive control technique for three-phase AFE rectifiers due to its simple and intuitive concept with fast dynamic responses and flexibility [22]-[24]. Fast and powerful microprocessors are available today to implement predictive control algorithms very easily since they require a higher number of calculations when compared with the classical control methods [25]-[29].

Despite the good performance of the MPC algorithm, there remain some limitations. One of the most important is a stability issue. Recently, the stability analysis of MPC controlled power converters, which are modeled as linear systems has been presented in [30]. The Lyapunov stability investigation of the MPC algorithm has been established in [31]. Furthermore, the Luenberger disturbance and its stability have been observed in [32]. So far, close-loop stability, which is one of the most important aspects of MPC controlled AFE rectifiers, has not been considered.

This paper proposes a model predictive control (MPC) algorithm which is applied in an AFE rectifier to improve its efficiency and performance. The efficiency of this MPC controlled AFE rectifier is compared with a VOC-based PWM rectifier to ensure the effectiveness of the proposed MPC algorithm. Moreover, the close-loop stability criterion of this MPC controlled AFE rectifier has been elaborately investigated with the discrete $\mathrm{z}$-domain response (Root locus, Bode plot, Nyquist diagram and Nichols chart) and the nonlinear simulation model. The rest of the paper is organized in the following manner. The system configuration and mathematical modeling of the three-phase AFE rectifier topology are elaborately described in section II. The formulation of the MPC method with a discrete time model, a cost function for the selection of the switching state and a detailed explanation of the control scheme are described in section III. Section IV provides an analyses of the stability criterion of the model predictive controlled AFE rectifier. The performance of a MPC controlled AFE rectifier prototype is verified and compared with a VOC-based PWM controlled rectifier in section V. Finally some conclusions are drawn in section VI.

\section{AFE RECTIFIER TOPOLOGY}

\section{A. System Configuration}

Fig. 1 shows the three-phase active front end (AFE) rectifier topology which consists of six IGBT-Diode $S_{1}-S_{6}$ switches. The AFE rectifier is connected with a three-phase voltage supply $v_{\mathrm{s}}$ using the line filter inductances $L_{\mathrm{s}}$ and resistances $R_{\mathrm{s}}$. A DC capacitor $C_{\mathrm{dc}}$ is connected across the resistive load to reduce the DC voltage ripple.

\section{B. Mathematical Modelling}

By applying Kirchhoff's voltage law at the ac side of the 
rectifier, the per-phase source-side voltage can be presented as in [33]:

$$
\begin{aligned}
& v_{\mathrm{Sa}}=L_{\mathrm{S}} \frac{d i_{\mathrm{Sa}}}{d t}+R_{\mathrm{S}} i_{\mathrm{sa}}+v_{\mathrm{ao}}-v_{\mathrm{no}} \\
& v_{\mathrm{sb}}=L_{\mathrm{S}} \frac{d i_{\mathrm{sb}}}{d t}+R_{\mathrm{S}} i_{\mathrm{sb}}+v_{\mathrm{bo}}-v_{\mathrm{no}} \\
& v_{\mathrm{Sc}}=L_{\mathrm{S}} \frac{d i_{\mathrm{Sc}}}{d t}+R_{\mathrm{S}} i_{\mathrm{Sc}}+v_{\mathrm{co}}-v_{\mathrm{no}}
\end{aligned}
$$

where, $v_{\mathrm{Sa}}, v_{\mathrm{Sb}}$ and $v_{\mathrm{Sc}}$ are the input phase voltages; and $i_{\mathrm{Sa}}, i_{\mathrm{sb}}$ and $i_{\mathrm{sc}}$ are the input phase currents of the three-phase voltage supply for the AFE rectifier.

These input phase voltages and currents can be described with a space vector model. Hence, the space vector model of the three-phase supply voltage and current are:

$$
\vec{v}_{\mathrm{S}}=\frac{2}{3}\left(v_{\mathrm{sa}}+\vec{\omega} v_{\mathrm{sb}}+\vec{\omega}^{2} v_{\mathrm{sc}}\right)
$$

and:

$$
\vec{i}_{\mathrm{S}}=\frac{2}{3}\left(i_{\mathrm{sa}}+\vec{\omega} i_{\mathrm{sb}}+\vec{\omega}^{2} i_{\mathrm{sc}}\right)
$$

where, $\vec{\omega}=e^{j 2 \pi / 3}=-\frac{1}{2}+j \sqrt{3} / 2$. From (1) to (5), the three-phase supply voltage vector can be rewritten as follows:

$$
\begin{aligned}
& \vec{v}_{\mathrm{S}}=L_{\mathrm{S}} \frac{d \overrightarrow{i_{\mathrm{S}}}}{d t}+R_{\mathrm{S}} \vec{i}_{\mathrm{S}}+\frac{2}{3}\left(v_{\mathrm{ao}}+\vec{\omega} v_{\mathrm{bo}}+\vec{\omega}^{2} v_{\mathrm{co}}\right) \\
& -\frac{2}{3}\left(v_{\mathrm{no}}+\vec{\omega} v_{\mathrm{no}}+\vec{\omega}^{2} v_{\mathrm{no}}\right)
\end{aligned}
$$

Note that the last term of (6) is zero since $\left(1+\vec{\omega}+\vec{\omega}^{2}\right)=0$, and the voltage vector $\vec{v}_{\mathrm{R}}$ generated by the AFE rectifier is:

$$
\vec{v}_{\mathrm{R}}=\frac{2}{3}\left(v_{\mathrm{ao}}+\vec{\omega} v_{\mathrm{bo}}+\vec{\omega}^{2} v_{\mathrm{co}}\right) .
$$

This voltage vector $\vec{v}_{\mathrm{R}}$ is determined from the DC-link voltage $V_{\mathrm{dc}}$ and the switching function vector $\vec{S}_{\mathrm{R}}$ as:

$$
\vec{v}_{\mathrm{R}}=\vec{S}_{\mathrm{R}} \times V_{\mathrm{dc}} .
$$

The value of the switching function vector $\vec{S}_{\mathrm{R}}$ depends on the switching states of the AFE rectifier. In order to avoid short circuits, the two switches in each leg of the rectifier should be operated in a complementary mode. Hence, the switching signals $S_{\mathrm{a}}, S_{\mathrm{b}}$ and $S_{\mathrm{c}}$ determine the switching states of the AFE rectifier as follows:

$$
\begin{aligned}
& S_{\mathrm{a}}= \begin{cases}1, & S_{1} \text { is on and } S_{2} \text { is off } \\
0, & S_{1} \text { is off } \text { and } S_{2} \text { is on }\end{cases} \\
& S_{\mathrm{b}}= \begin{cases}1, & S_{3} \text { is on and } S_{4} \text { is off } \\
0, & S_{3} \text { is off and } S_{4} \text { is on }\end{cases}
\end{aligned}
$$

$$
S_{\mathrm{c}}= \begin{cases}1, & S_{5} \text { is on and } S_{6} \text { is off } \\ 0, & S_{5} \text { is off and } S_{6} \text { is on }\end{cases}
$$

Therefore, the switching function vector $\vec{S}_{\mathrm{R}}$ of the AFE rectifier can be expressed as:

$$
\vec{S}_{\mathrm{R}}=\frac{2}{3}\left(S_{\mathrm{a}}+\vec{\omega} S_{\mathrm{b}}+\vec{\omega}^{2} S_{\mathrm{c}}\right)
$$

The input current dynamics of (6) becomes:

$$
\frac{d \overrightarrow{i_{\mathrm{S}}}}{d t}=\frac{1}{L_{\mathrm{S}}}\left(\vec{v}_{\mathrm{S}}-\vec{v}_{\mathrm{R}}-R_{\mathrm{S}} \vec{i}_{\mathrm{S}}\right)
$$

\section{FORMULATION OF THE MPC ALGORITHM}

The MPC algorithm utilizes the discrete nature of the switching devices and the finite number of valid switching states of the power converter. In order to select the appropriate switching state to be applied for firing the converter switch, a selection criterion must be defined with a cost function which measures the error between the reference and predicted values. Then, the state that minimizes the cost function is selected for switching in the next sampling interval.

\section{A. Discrete Time Model}

It is important to derive a discrete time model for the power converter system because the predictive controller is formulated in the discrete time domain. To estimate the next sampling value of the input current considering the current and voltage measurements at the $k^{\text {th }}$ sample time, a discrete model of the input side should be employed.

For $k T_{\mathrm{s}} \leq t \leq(k+1) T_{\mathrm{s}}$, with $T_{\mathrm{s}}$ being the sampling time, the system model derivative $d x / d t$ can be expressed from the Euler approximation to increase the fast dynamic response as:

$$
\frac{d \vec{i}_{\mathrm{S}}}{d t} \approx \frac{i_{\mathrm{S}}(k+1)-i_{\mathrm{S}}(k)}{T_{\mathrm{S}}} .
$$

Using the above approximation, the discrete time model of the predictive input currents for the next $(k+1)$ sampling instant of the AFE rectifier can be derived as follows:

$$
\vec{i}_{S}(k+1)=\left(1-\frac{R_{S} T_{S}}{L_{S}}\right) \vec{i}_{S}(k)+\frac{T_{S}}{L_{S}}\left[\vec{v}_{S}(k)-\vec{v}_{R}(k)\right]
$$

\section{B. Cost Function}

The main objective of the MPC algorithm is to minimize the error with a fast dynamic response between the predicted and reference values of the discrete variables. To achieve this objective, an appropriate cost function $e$ is defined with a measurement of the predictive input error. Hence, the cost function for the active front end rectifier can be expressed with the absolute error between the predictive and reference values of the input current as:

$$
\vec{e}=\left|\vec{i}_{\text {ref }}(k+1)-\vec{i}_{\mathrm{p}}(k+1)\right|
$$




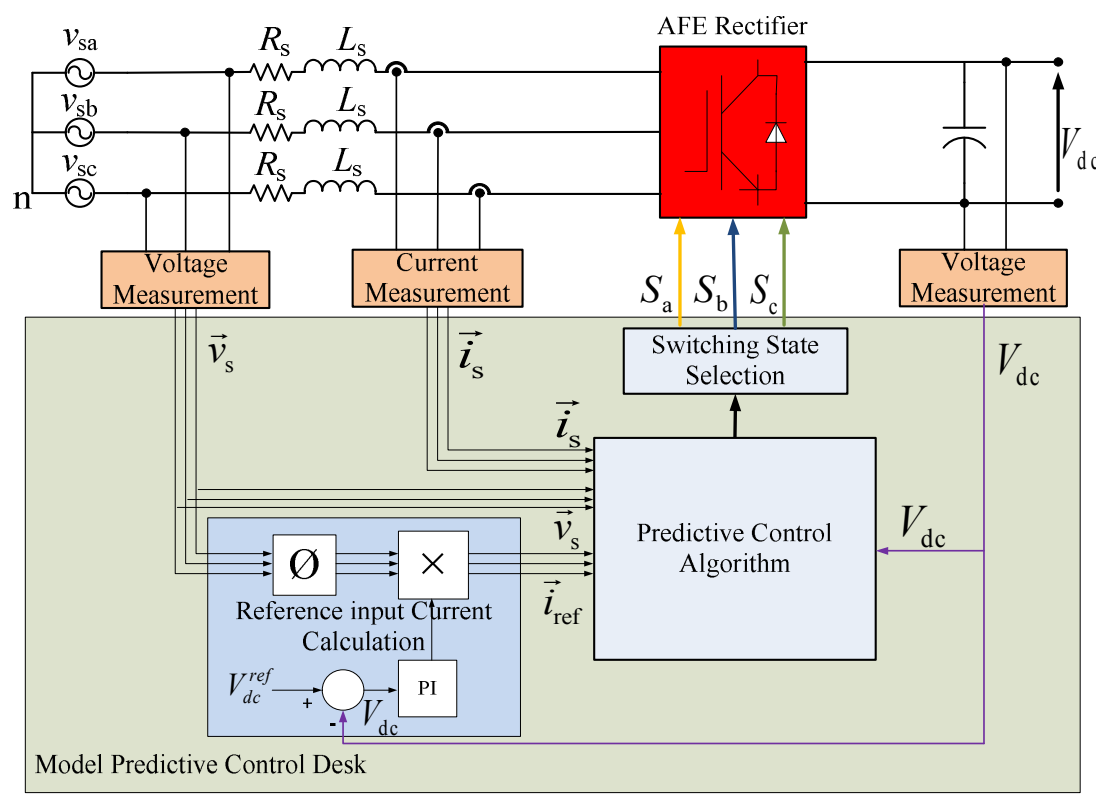

Fig. 2. Model predictive control scheme.

where, $e$ is the cost function for the AFE rectifier. The reference and predicted input currents of the AFE rectifier are:

$$
\vec{i}_{\text {ref }}(k+1) \text { and } \vec{i}_{\mathrm{p}}(k+1) \text {. }
$$

\section{Control Scheme}

Fig. 2 shows the proposed control strategy of the model predicative control algorithm to operate the active front end (AFE) rectifier. The three-phase input current of the rectifier $\vec{i}_{\mathrm{S}}(k)$ is measured and the future value of this current $\vec{i}_{\mathrm{S}}(k+1)$ is predicted by using (15) for each of the eight possible switching vectors $\vec{S}_{\mathrm{R}}$. The future value of the three-phase input supply current $\vec{i}_{\mathrm{S}}(k+1)$ is compared with the reference current $\vec{i}_{\text {ref }}(k+1)$ by utilizing the cost function $e$ of (16). The reference current $\vec{i}_{\text {ref }}(k+1)$ is calculated from the three-phase input supply voltage vector $\vec{v}_{S}$ and the resistive load terminal DC voltage $V_{\mathrm{dc}}$ by using a PI controller. Finally, the switching states of the AFE rectifier which minimize the cost function, are selected for the next sampling interval.

\section{Transfer Function}

The transfer function of the MPC controlled AFE rectifier can be derived from its simplified control scheme, which is presented in Fig. 2. This control structure consists of two cascaded control loops. These are an inner input current control loop and an outer DC link voltage control loop.

1) Current Control Loop: Fig. 3(a) shows a simplified block diagram of the inner input current control loop while considering that the DC link voltage is constant. Therefore, the variation of the supply voltage $\left(\Delta \vec{v}_{\mathrm{S}}\right)$ is the only disturbance signal. The error voltage $v_{\text {err }}$ is referred to as the difference value of the reference and the predicted values of the converter voltage.

There are many delays in the current control loop such as the processing time of the MPC algorithm, the $\mathrm{A} / \mathrm{D}$ conversion time, and the delay time of the converter, which have to be taken into account for the control design. Generally, all delays are grouped together to form a single first-order delay element with an equivalent time constant $\left(T_{\text {eq }}\right)$. In the literature [34]-[36], it has been stated that the converter delay with the MPC algorithm is 1.5 times its sampling time at a $200 \mu$ s sampling time with a TMS320C31 DSP processor. The choice of the equivalent delay $\left(T_{\mathrm{eq}}\right)$ mostly depends on the sampling time and speed of the real time interfacing processors which are usually synchronized. The proposed MPC control scheme of Fig. 2 illustrates the relationship between the sampling instants and the MPC switching signals. It is applied to control the three-phase IGBT converter of the laboratory setup. The MPC algorithm produces a switching signal by accurately tracking the reference value which is symmetrical around the sampling instant. This characteristic of the MPC controlled AFE rectifier makes it possible to sample ripple-free currents. In addition, from a signal point of view, it makes low pass filtering without delay possible. The computation time of the control algorithm $\left(T_{\mathrm{c}}\right)$ must be shorter than half of the sampling time $\left(T_{\mathrm{s}}\right)$. From a control point of view it is necessary to define the total delay that varies in the range from $0.5 T_{\mathrm{s}}$ to $T_{\mathrm{s}}$ depending on the actual control signal. The statistical execution delay of the MPC controller is assumed 


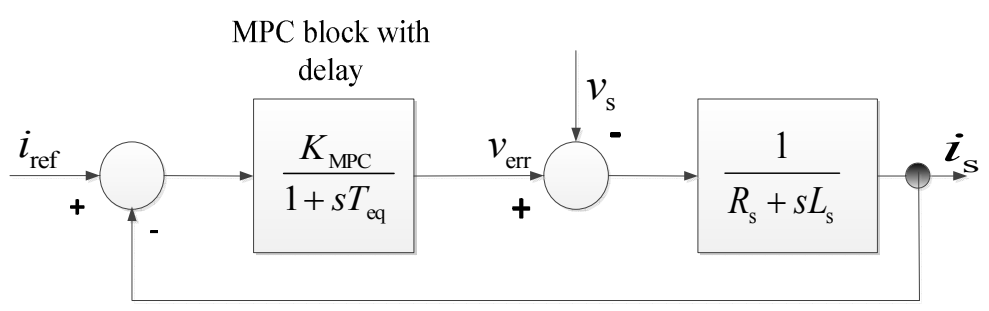

(a)

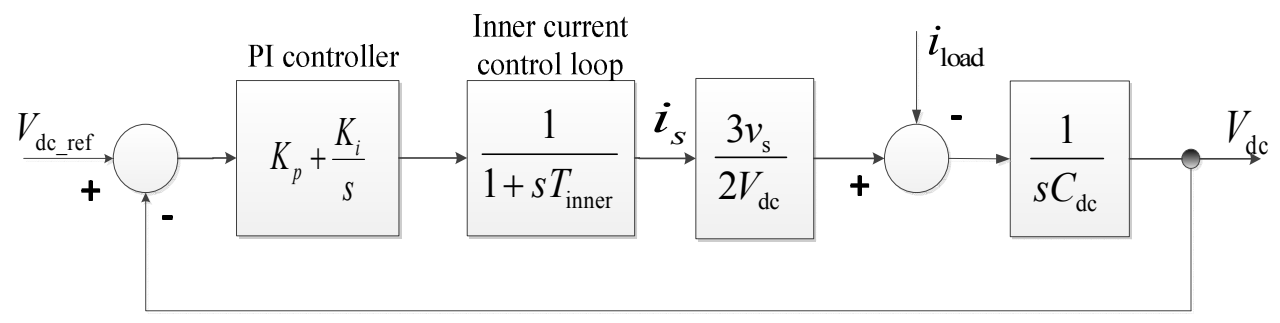

(b)

Fig. 3. Simplified block diagram of (a) inner input current control loop and (b) outer DC link voltage control loop.

to be $10 \%$ of the sampling time $T_{\mathrm{s}}$ (in case of a powerful Dspace TMS320F240 processor), where $T_{\mathrm{s}}$ is $50 \mu \mathrm{s}$. In addition, considering that the $\mathrm{A} / \mathrm{D}$ conversion delay is $5 \%$ of the sampling time $T_{\mathrm{s}}$, the equivalent time constant $T_{\text {eq }}$ can be obtained by utilizing the equation of $T_{\mathrm{eq}}=T_{\mathrm{s}}-(10 \%+5 \%) T_{\mathrm{s}}$ as:

$$
T_{\text {eq }}=0.85 T_{\mathrm{S}} \text {. }
$$

The proposed MPC controlled AFE rectifier uses only a $R L$ filter to connect with a three-phase supply voltage. As a result, the control plant becomes a first-order delay element with a transfer function. Hence, the transfer function of the current control loop can be derived with the equivalent time constants and the input $R L$ filter as:

$$
G_{\mathrm{i}}(s)=\frac{K_{\mathrm{MPC}}}{s^{2} T_{\mathrm{eq}} L+s\left(R T_{\mathrm{eq}}+L\right)+\left(R+K_{\mathrm{MPC}}\right)}
$$

where, $K_{\mathrm{MPC}}$ is the constant gain of the model predictive algorithm which can be defined with the amplitude ratio of the measured and reference currents.

\section{2) DC Link Voltage Control Loop}

The dynamic model equation at the DC link voltage of the active front end rectifier is:

$$
C_{\mathrm{dc}} \frac{d V_{\mathrm{dc}}}{d t}=i_{\mathrm{dc}}-i_{\text {load }}=\frac{3 v_{\mathrm{S}} i_{\mathrm{S}}}{2 V_{\mathrm{dc}}}-i_{\text {load }} .
$$

The simplified DC link voltage control loop is presented in Fig. 3(b). Thus, the transfer function of this DC link voltage control loop can be obtained from the PI controller, the inner current loop delay element $T_{\text {inner }}=T_{\text {eq }}$ and the DC link voltage dynamic equation as:

$$
G_{\mathrm{V}}(s)=\frac{s\left(3 v_{\mathrm{s}} K_{\mathrm{p}}\right)+3 v_{\mathrm{S}} K_{\mathrm{i}}}{s^{2}\left(2 V_{\mathrm{dc}} C_{\mathrm{dc}} T_{\text {inner }}+s\left(2 V_{\mathrm{dc}} C_{\mathrm{dc}}+3 v_{\mathrm{s}} K_{\mathrm{p}}\right)+3 v_{\mathrm{s}} K_{\mathrm{i}}\right.} .
$$

\section{STABILITY ANALYSIS}

Although the model predictive control system is composed of inner current and outer voltage control loops, the inner input current control loop is responsible for the overall control system stability [9], [37], [38]. Therefore, the stability analysis of the inner current control loop is carried out with two methods. The first one is a discrete z-domain analysis, which is carried-out by assuming a sample delay with the Root locus, Bode plot, Nyquist diagram and Nichols chart. Afterwards, a Matlab/Simulink model is developed to investigate the stability of the MPC controlled AFE rectifier by means of a nonlinear model.

\section{A. Discrete Z-Domain Analysis}

The z-domain stability analysis is based on the current closed-loop transfer function, MPC system plant, delay element and iron losses in the inductors. The Root-locus is a powerful method for stability analysis and for measuring the transient response of close-loop control systems which is used for observing the effect of loop gain variations. Moreover, this method can plot the roots of any polynomial with real parameters that hamper the system linearity. Fig. 4(a) depicts the root locus of the inner close loop current control transfer function which is presented in (18). The root locus technique confirms the stability of the model predictive control since the locus path is lying on the left half of the S-plane.

The stability of the close-loop control system is further analyzed with the discrete z-domain frequency response because of the ambiguities of the root locus sketch, nonlinear system stability, and lead compensators for steady-state errors and transient response. The Nyquist criterion can determine the effects of a time delay on the relative stability of a 


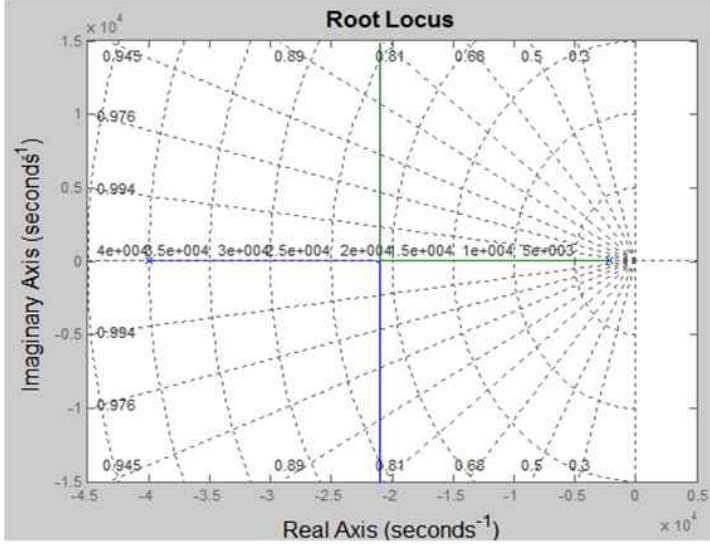

(a)

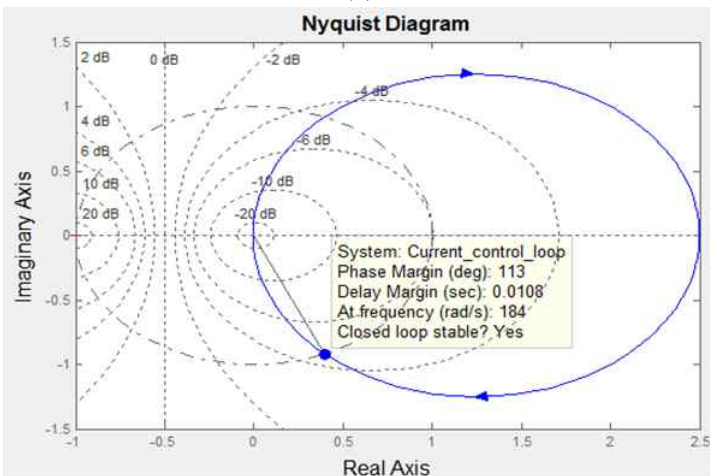

(b)

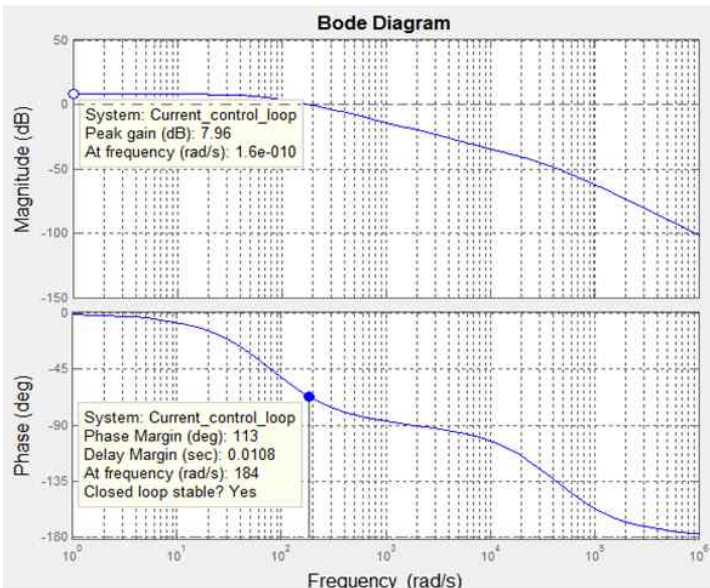

(c)

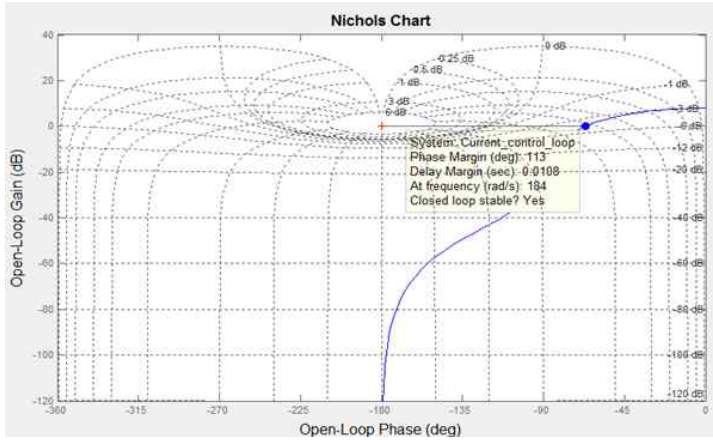

(d)

Fig. 4. The stability analysis of input current control loop with (a) Root Locus technique, (b) Nyquist diagram (c) Bode plot, and (d) Nichols chart.
TABLE I

SiMUlATION AND EXPERIMENTAL PARAMETERS

\begin{tabular}{|l|c|c|c|}
\hline \multicolumn{4}{|c|}{ Parameter values and unit } \\
\hline $\begin{array}{l}\text { Variables and } \\
\text { Parameters }\end{array}$ & Symbols & Values & Unit \\
\hline Power Rating & $\mathrm{P}$ & 3.0 & $\mathrm{~kW}$ \\
\hline Supply Voltage & $v_{\mathrm{s}}$ & 110 & $\mathrm{~V}_{\mathrm{rms}}$ \\
\hline Supply Frequency & $f_{\mathrm{s}}$ & 50 & $\mathrm{~Hz}$ \\
\hline Reference DC-link & $V_{\mathrm{dc}}$ & 270 and 320 & $\mathrm{~V}$ \\
\hline Input Filter Inductance & $L_{\mathrm{s}}$ & 5 & $\mathrm{mH}$ \\
\hline Input Filter resistance & $R_{\mathrm{s}}$ & 0.1 & $\Omega$ \\
\hline Sampling Time & $T_{\mathrm{s}}$ & 50 & $\mu \mathrm{s}$ \\
\hline Load resistance & $R_{\mathrm{Load}}$ & 50 & $\Omega$ \\
\hline Capacitor value & $C_{\mathrm{dc}}$ & 1000 & $\mu \mathrm{F}$ \\
\hline
\end{tabular}

close-loop system. Fig. 4(b) shows a Nyquist plot of the current control loop which ensures the close loop stability of the system. Afterwards, a bode plot which permits the display of wider frequency ranges in a single plot is used to analyze the system stability for dynamic compensation and actual transfer function construction.

A bode plot of the MPC controlled current loop is illustrated in Fig. 4(c), which shows that the measured gain margins are infinite and the phase margins are about $113^{\circ}$. These results with a bode plot ensure that the control system is stable. In addition, the delay margin is very small when compared to the system time constant which ensures a fast dynamic response. Finally, the stability of the MPC controlled AFE rectifier is investigated with a Nichols diagram to check the close loop system stability with resonance peak requirements. The Nichols chart presented in Fig. 4(d) also confirms the stability of the inner current control loop.

\section{B. Nonlinear Model Stability Analysis}

The stability analysis of the MPC controlled AFE rectifier is performed with a linear discrete $\mathrm{z}$-domain investigation, in the previous section, neglects the nonlinear criteria such as: the unsymmetrical three-phase supply, the existence of higher harmonics in the converter input voltage, the cross-coupling effect and the time delay variation. To analyze the influence of these nonlinearities and simplifications of practical systems, a nonlinear simulation model is developed with MATLAB/Simulink software which is presented in Fig. 5. The simulation parameters are depicted in Table I and the simulation has been carried out with a sampling time of $T_{\mathrm{s}}=50 \mu \mathrm{s}$.

The simulation structure is equal to the control scheme shown in Fig. 2, which consist of control and power circuits. The filter inductance $L_{\mathrm{s}}$ and resistance $R_{\mathrm{s}}$ are modeled with the iron and copper losses resistances, which are connected with a three-phase programmable voltage source. The AFE rectifier consists of six IGBT-diode switches which are 

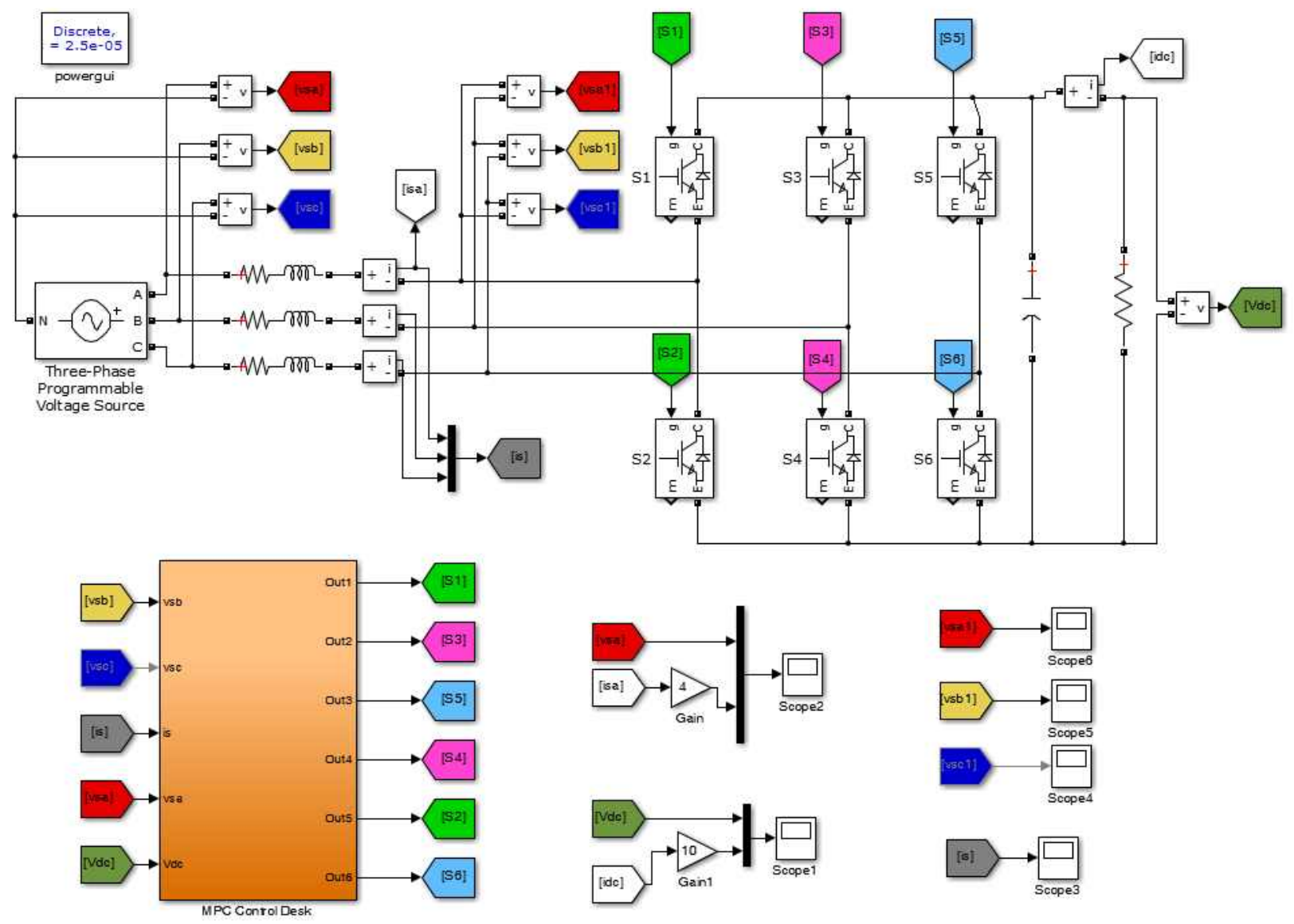

Fig. 5. Nonlinear simulation model of MPC controlled AFE rectifier.

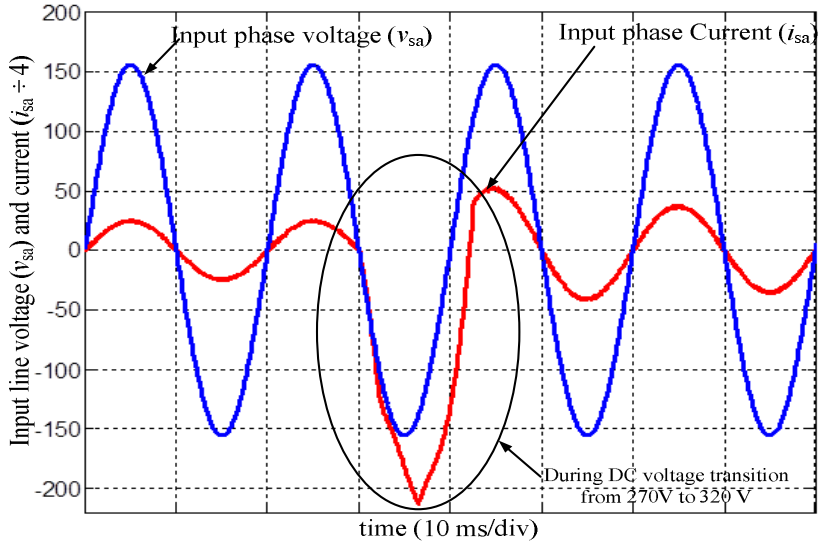

Fig. 6. Simulation results of input phase voltage and current with reference DC voltage change from $270 \mathrm{~V}$ to $320 \mathrm{~V}$.

modeled with appropriate conduction losses. Again the MPC controller is designed with a delay time $T_{\mathrm{d}}$ that is $10 \%$ of the sampling time $T_{\mathrm{s}}$. To compare the stability criteria of the MPC controller obtained by the discrete $\mathrm{z}$-domain technique the parameters in Table I are used.

The output DC-link reference voltage $V_{\mathrm{dc}}$ is varried from $270 \mathrm{~V}$ to $320 \mathrm{~V}$ to check the stability of the control system by means of the nonlinear method. Fig. 6 shows the simulation output of both the supply phase voltage and the current which
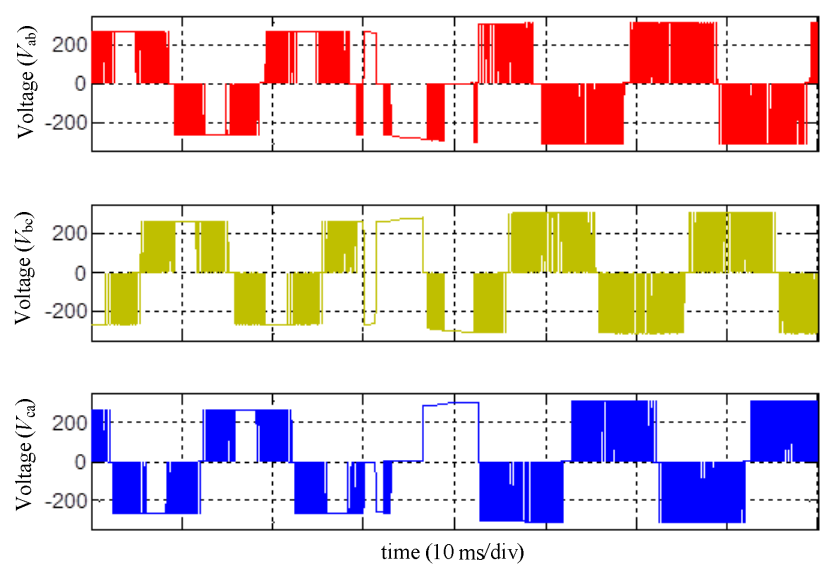

Fig. 7. Phase to phase voltage at the AFE rectifier end during reference DC voltage change from $270 \mathrm{~V}$ to $320 \mathrm{~V}$.

reveals the unity power factor because the angle between the input voltage and current is $0^{\circ}$.

Fig. 7 shows the phase to phase voltages at the AFE rectifier end. On the other hand, the three-phase current drawn by the active front end rectifier is presented in Fig. 8. The result in Fig. 8 shows that the output phase current is accurately tracking the reference value, which verifies the feasibility of the model predictive control method. Moreover, 


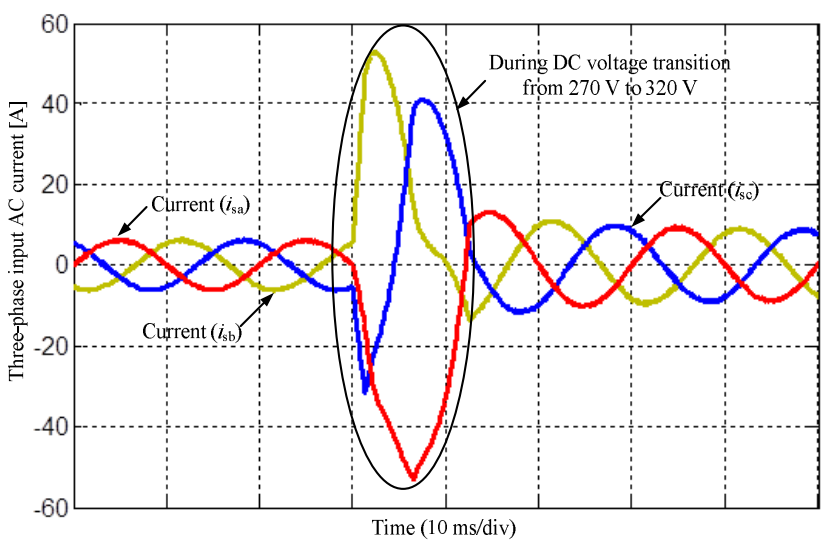

Fig. 8. Three-phase input current $[\mathrm{A}]$ with step change of DC reference voltage.

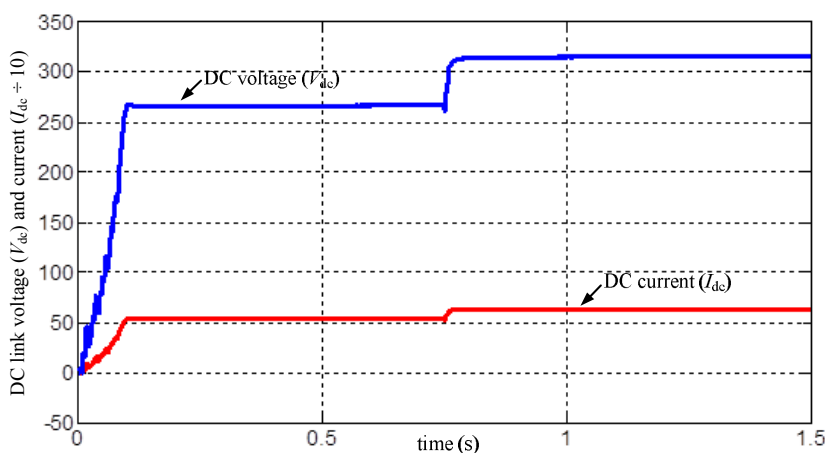

Fig. 9. Output DC voltage Vdc [V] and current $(\mathrm{Idc} \div 10)[\mathrm{A}]$ with step change.

the step change of the three-phase current due a change in the DC reference voltage confirms the stability of the control algorithm and the fast dynamic response.

Fig. 9 shows the very good tracking of the DC-link reference voltage of $270 \mathrm{~V}$ to $320 \mathrm{~V}$. The figure also presents the DC current, and the average value of this current is approximately $5.20 \mathrm{~A}$ and $6.17 \mathrm{~A}$ for the $\mathrm{DC}$ reference voltages of $270 \mathrm{~V}$ and $320 \mathrm{~V}$, respectively. The DC voltage pulsations are negligible. The stability of the MPC controlled active front end rectifier can also be analyzed with the output DC link voltage and current. The steady state output DC voltage and current are linear in a wide time-range-change verifying the stability of the MPC algorithm.

\section{Stability Analysis for Input AC Voltage Variations}

The stability of the proposed MPC controlled active front end rectifier has been analyzed based on input $\mathrm{AC}$ voltage variations. The $\mathrm{AC}$ input voltage has been varied sequentially as 1: $0.8: 1.2: 1$ of its per-unit (pu) value with respect to time. The result in Fig. 10 shows the supply phase voltage and current which reveal the unity power factor with variations of the input $\mathrm{AC}$ voltage. In addition, the three-phase $\mathrm{AC}$ current variations drawn by the $\mathrm{AFE}$ rectifier due to input $\mathrm{AC}$ voltage variations are also presented in Fig. 11. The result in Fig. 11 shows that the output phase current accurately tracks the reference value and reached its steady state condition with a

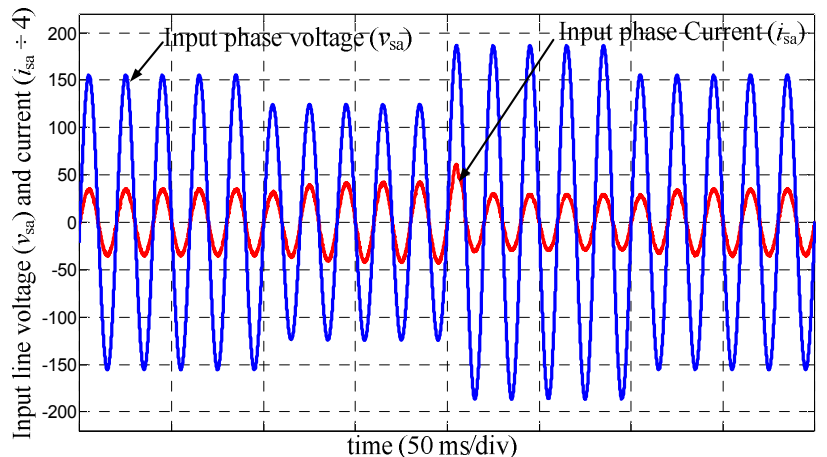

Fig. 10. The variation of input phase voltage $\left(v_{\mathrm{sa}}\right)$ and current $\left(i_{\mathrm{sa}}\right)$ with the variation of input $\mathrm{AC}$ voltage.

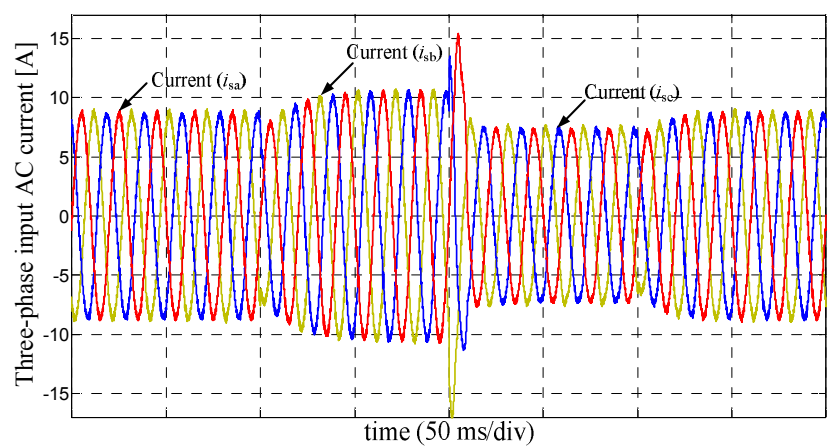

Fig. 11. The variation of the three-phase input current $[\mathrm{A}]$ with the variation of input $\mathrm{AC}$ voltage.

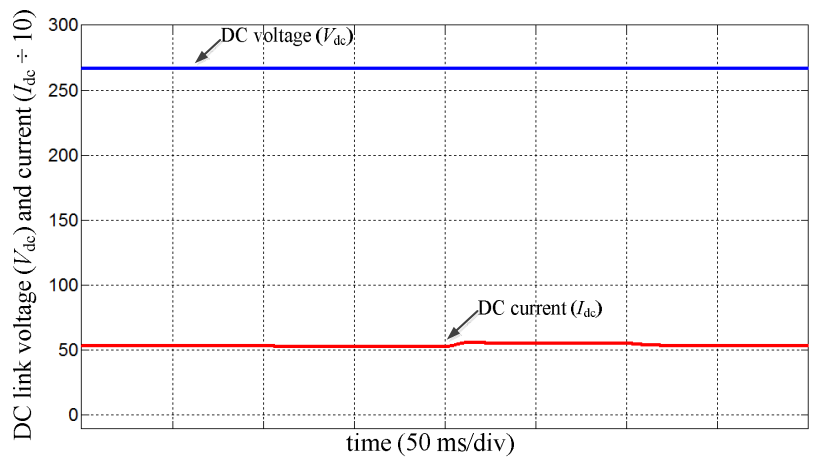

Fig. 12. The variation of the DC-linked voltage and current with the variation of input $\mathrm{AC}$ voltage.

very fast dynamic response, which verifies the stability and effectiveness of the MPC controlled AFE rectifier in the case of input AC voltage variations. Moreover, the stability of the proposed control algorithm can be further confirmed with variations of the DC-link voltage and current as shown in Fig. 12. The DC-link voltage is constant due to the fixed reference value, while the DC current varies with respect to input $\mathrm{AC}$ voltage variations since the load is constant.

\section{Stability Analysis for Load Variations}

The stability of the proposed MPC controlled AFE rectifier has also been tested with load variations in the following subsection. The load resistance has been changed from $100 \Omega$ to $50 \Omega$ and then back to $100 \Omega$ to create the load variation condition. The result in Fig. 13 shows the supply phase 


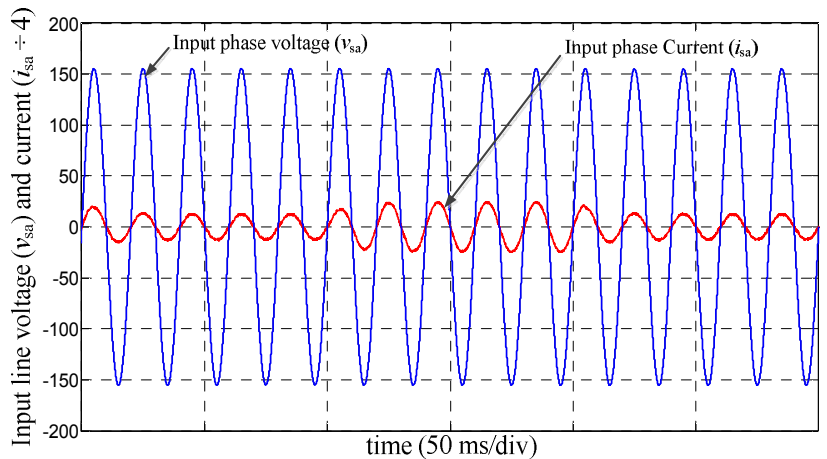

Fig. 13. The variation of input phase voltage $\left(v_{\mathrm{sa}}\right)$ and current $\left(i_{\mathrm{sa}}\right)$ with the variation of load.

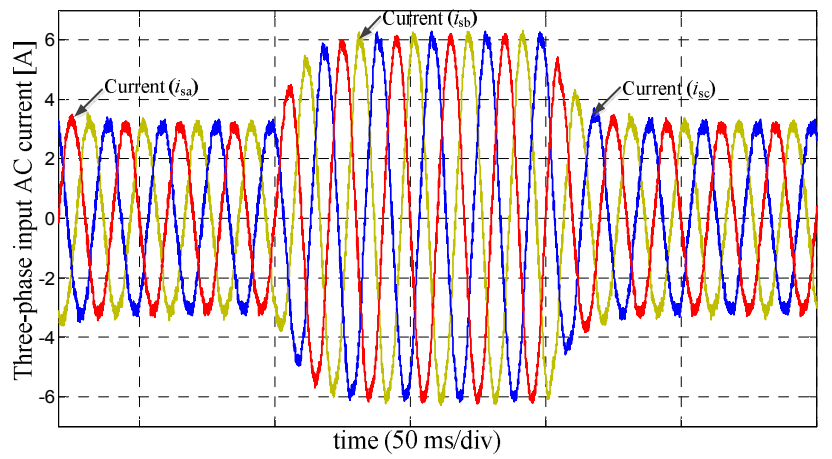

Fig. 14. The variation of the three-phase input current [A] with the variation of load.

voltage and current which confirms the unity power factor with a sudden change of the $\mathrm{AC}$ input current due to variations of the load. The three-phase AC current variations drawn by the AFE rectifier are also presented in Fig. 14, which shows that the output phase current accurately tracks the reference value and reaches its steady state condition with a very fast dynamic response. This verifies the stability and effectiveness of the MPC controlled AFE rectifier in the case of load variations. Moreover, the stability of the proposed control algorithm can be further confirmed from the response of the DC-link voltage and current shown in Fig. 15. The DC-link voltage is constant due to the fixed reference value, while the DC current varies with respect to load variations since the input AC voltage is constant.

\section{PERFORMANCE INVESTIGATION}

The performance of the MPC controlled AFE rectifier is investigated with $3.0 \mathrm{~kW}$ experimental configurations. The experimental verification is carried out by using the rapid prototyping and real-time interface system in dSPACE with a DS1104 control card which consist of a Texas Instruments TMS320F240 sub-processor and a Power PC 603e/250 MHz main processor. The dSPACE control desk works together with MATLAB/Simulink ${ }^{\circledR}$ R2011b real-time workshop and real-time interface (RTI) control cards to implement the proposed MPC algorithm to the active front end (AFE) rectifier hardware prototype.

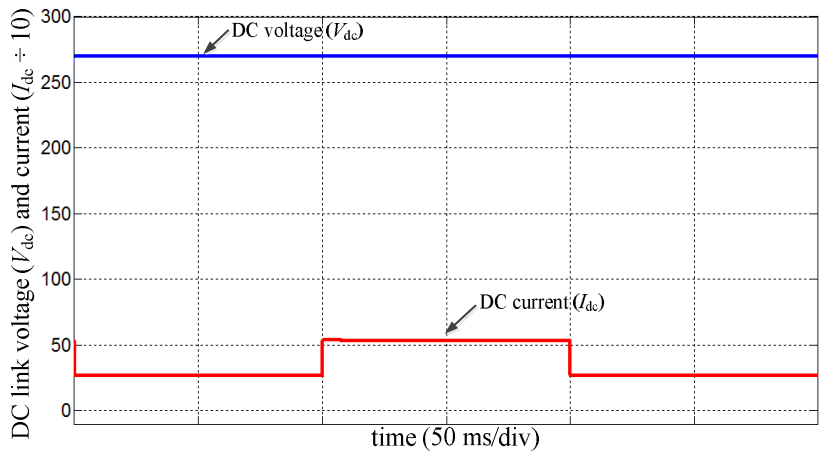

Fig. 15. The variation of the DC-linked voltage and current with the variation of input $\mathrm{AC}$ voltage.

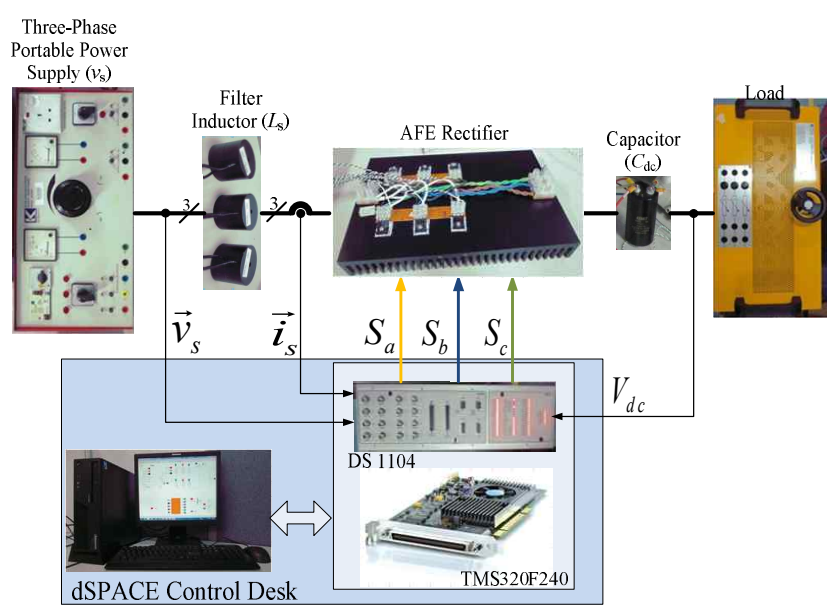

Fig. 16. Schematic layout.

The schematic layout and the experimental system of the MPC controlled AFE rectifier are presented in Figs. 16 and 17. A three-phase portable power supply [KOSIJAYA, MODEL: KA19530] was used for the voltage supply and a STMICROELECTRONICS - STGW20NC60VD - IGBT, $600 \mathrm{~V}, 20 \mathrm{~A}$ was used as a power devices in the active front end (AFE) rectifier. The parameters shown in Table I are employed.

\section{A. Experimental Results}

The voltage is measured with a differential probe [PINTEK DP-25] and the current is measured with a current transducer [LEM LA 25-NP]. The current transducer output voltage gain is set at $1.0 \mathrm{~V}$ output to measure 1.0 A currents. Fig. 18 shows the measured voltage and current of phase A with the DC link reference voltage step change response. This demonstrates the unity power factor and stability of the controller as described in section IV.

The performance of the model predictive control for AFE rectifiers is verified with the measured three-phase input current and the phase-to-phase voltage at the rectifier end, which are depicted in Figs. 19 and 20, respectively. The three-phase current accurately tracks the reference current albeit a transient time of $0.02 \mathrm{sec}$. This ensures the accuracy and fast dynamic response of the control algorithm. The 


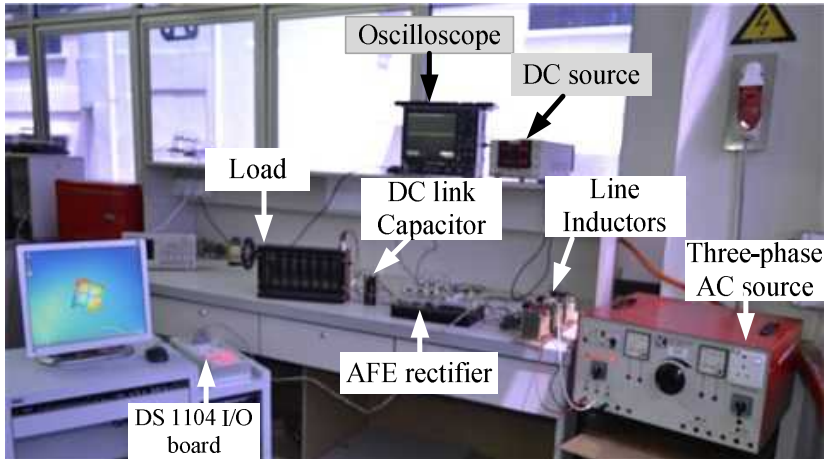

Fig. 17. Experimental system of AFE rectifier with model predictive control algorithm.

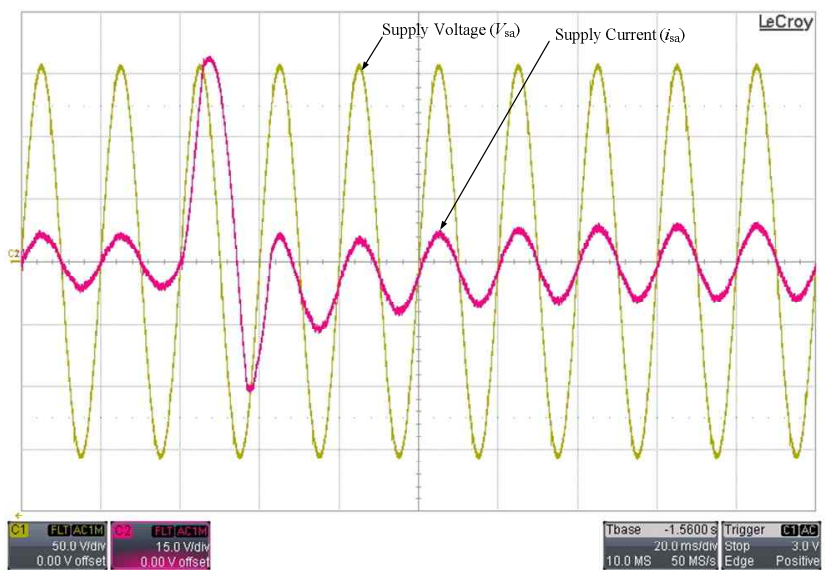

(a)

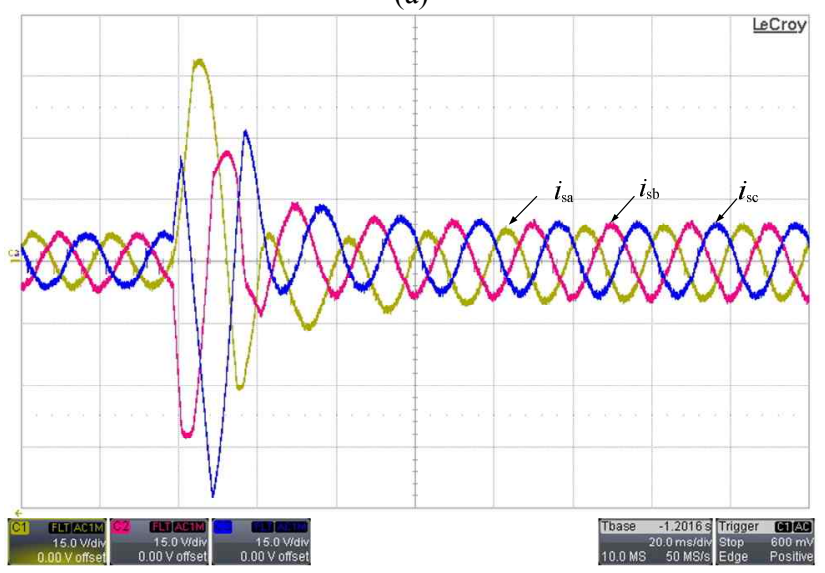

(b)

Fig. 18. Experimental results. (a) Input voltage $V_{\text {sa }}[50 \mathrm{~V} / \mathrm{div}]$ and current $i_{\mathrm{sa}}[15 \mathrm{~A} / \mathrm{div}]$ of phase A with step change of DC reference voltage. (b) AC input current [15A/div].

collector-emitter voltage during a step change in the DC reference voltage of the AFE rectifier is presented in Fig. 21.

The stability and performance of the MPC controlled AFE rectifier can also be analyzed with the output DC link voltage and current under the steady state and transient conditions. Fig. 22 shows that the steady state output DC voltage and current are linear in a wide time range with very low voltage and current ripples. This indicates the good performance of the

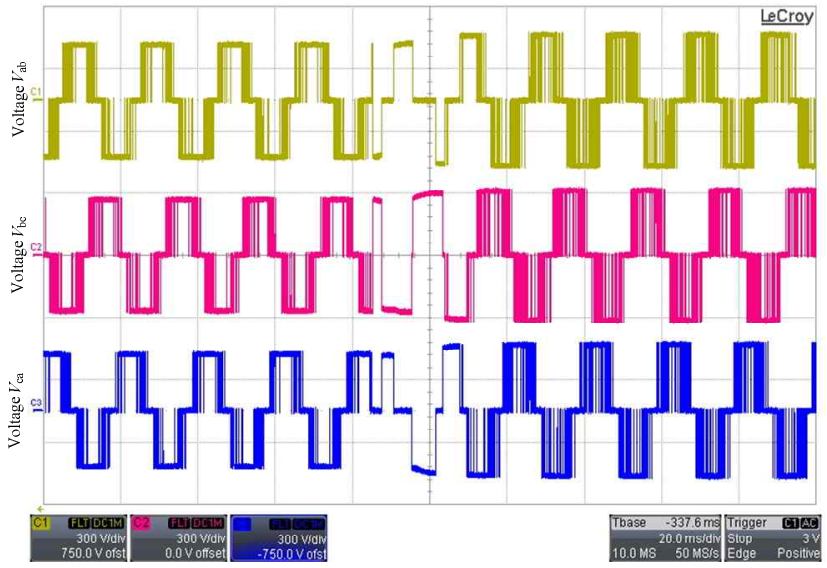

Fig. 19. Experimental results of phase to phase input voltage $[300 \mathrm{~V} / \mathrm{div}]$ at the AFE rectifier end.

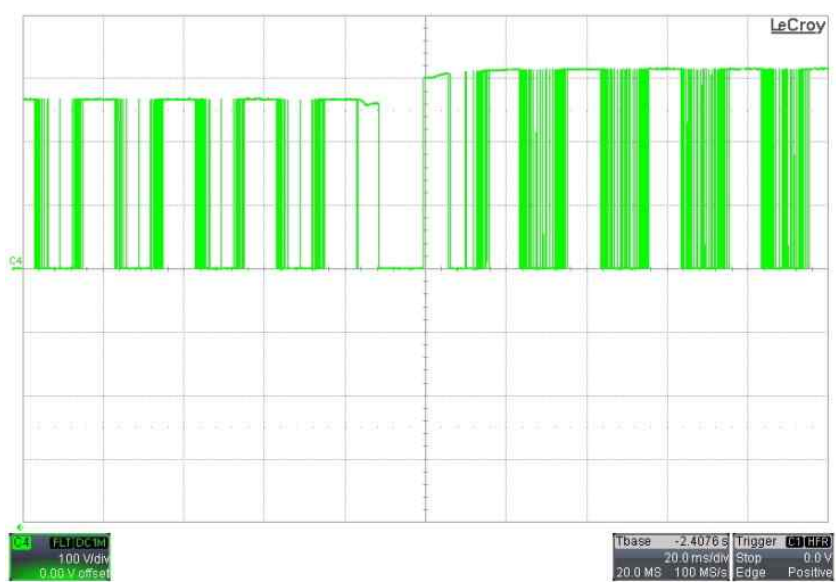

Fig. 20. Experimental results of collector-emitter voltage $[100 \mathrm{~V} / \mathrm{div}]$ during the step change in DC reference voltage.

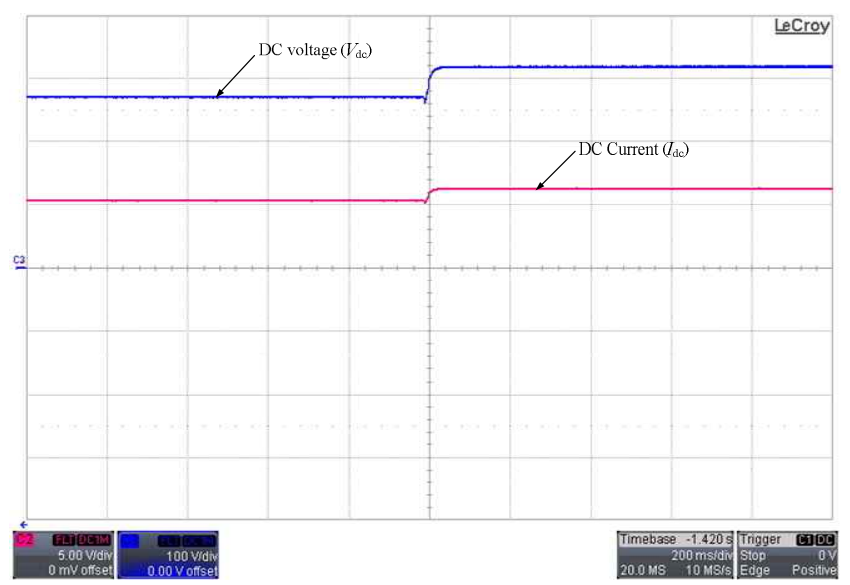

Fig. 21. Experimental results of output DC voltage $[100 \mathrm{~V} / \mathrm{div}]$ and current $[5 \mathrm{~A} / \mathrm{div}]$ of the AFE rectifier at $1.38 \mathrm{~kW}$ and 1.98 $\mathrm{kW}$ power transfer.

MPC algorithm. The output DC voltage and current increase rapidly with a step change in the DC reference voltage, confirming the effectiveness and stability of the MPC algorithm. 


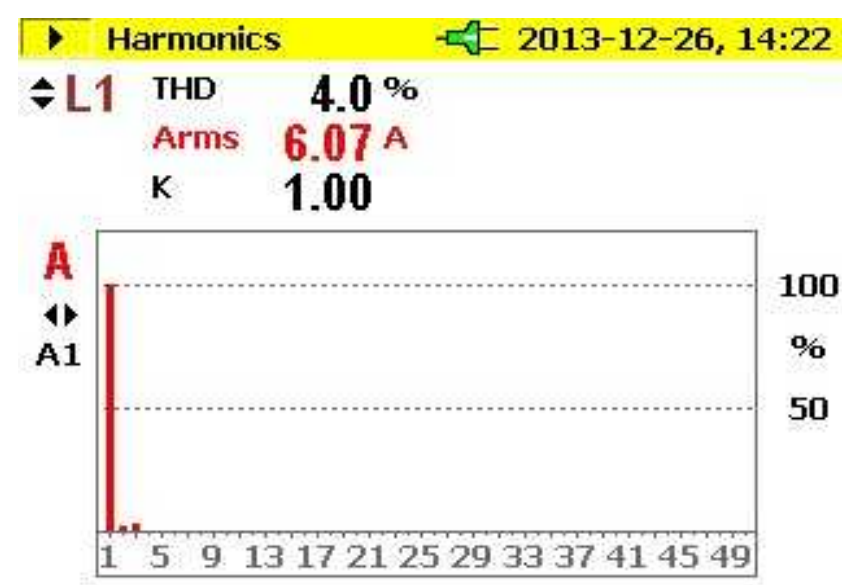

Fig. 22. Total harmonic distortion (THD) of input current at $320 \mathrm{~V}$ DC reference voltage.

Finally, the harmonic analysis of the three-phase input current of the AFE rectifier is illustrated in Fig. 23. This shows that the total harmonic distortion (THD) is $4.0 \%$. The THD of the input current is measured with a FLUKE 1735 Power Logger. The accuracy of this power logger is $\pm 0.2 \%$ of its full scale.

\section{B. Rectifier Efficiency}

The efficiency of the MPC controlled AFE rectifier is measured with a FLUKE 1735 Power Logger. The accuracy of this power logger is $\pm 0.2 \%$ of its full scale. The efficiency of the AFE rectifier is measured using the MPC method in the power transfer ranges from $0.5 \mathrm{~kW}$ to $3.0 \mathrm{~kW}$. In order to confirm the effectiveness of the MPC algorithm, the efficiency of a MPC controlled AFE rectifier is compared with that of a VOC-based PWM controlled AFE rectifier, as shown in Fig. 24. The voltage-oriented control (VOC) scheme decomposes the active and reactive power in the stationary $\alpha-\beta$ co-ordinate and synchronizes the powers with rotating $d-q$ reference frames by characterizing the current control loops using two PI controllers. This VOC-based PWM method is applied to a $3.0 \mathrm{~kW}$ AFE rectifier topology while employing the same parameters and measurement techniques as in the MPC algorithm.

The switching frequency of the VOC-based PWM controller has been fixed at $5 \mathrm{kHz}$, since the approximate average switching frequency of the MPC algorithm is $5 \mathrm{kHz}$ for a $50 \mu$ s sampling time due to its variation characteristics. The amount of power transfer associated with the MPC controlled AFE rectifier mainly depends on the switching frequency which has been presented in Fig. 25. From this figure, it is clear that the maximum power $(3.0 \mathrm{~kW})$ has been transferred at a $5 \mathrm{kHz}$ switching frequency at a $50 \mu \mathrm{s}$ sampling time by accurate tracking of the reference value.

The MPC algorithm is comparatively simple when compared to the VOC-based PWM technique since it uses only one PI regulator. The MPC algorithm accurately tracks

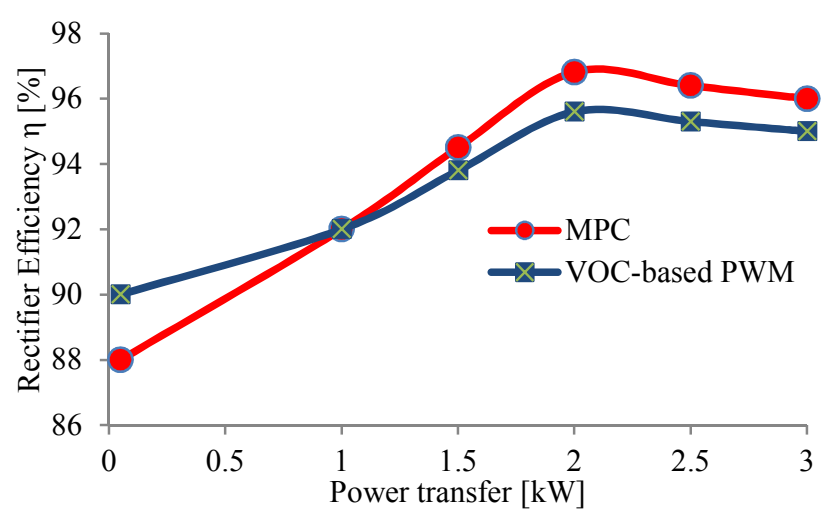

Fig. 23. Efficiency comparison between MPC and VOC-based PWM control method.

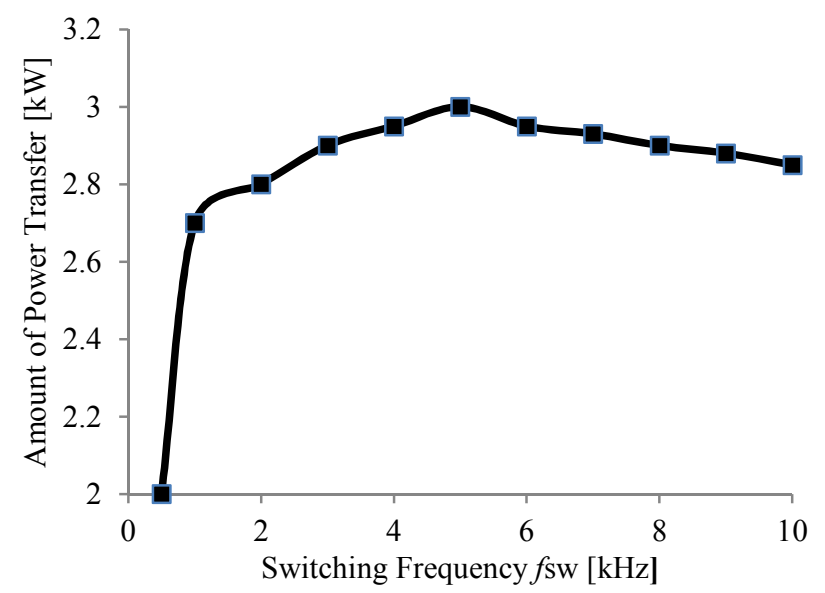

Fig. 24. Measured power transfer with different switching frequency of the MPC controlled AFE rectifier.

the reference value and generates an optimum switching signal by utilizing the cost function in every sampling instant of $T_{\mathrm{s}}$. The optimum switching signal reduces the undesired conduction losses of the IGBT switches. Moreover, the unity power factor is also maintained with the MPC algorithm since it accurately tracks the reference current and keeps zero phase-shift between the input AC voltage and current. Hence, the efficiency of the MPC controlled AFE rectifier has been increased with reduced IGBT switching losses and minimized reactive power. Although the MPC algorithm has a variable switching frequency problem, the efficiencies associated with the MPC control are higher when compared with the VOC-based PWM control method. Fig. 24 confirms that a maximum efficiency has been achieved at $2.0 \mathrm{~kW}$ of power transfer for both control methods, where the converter efficiency using the MPC method is $96.82 \%$, while the efficiency is $95.6 \%$ using the VOC-based PWM control method. It can be seen that the efficiencies of the AFE rectifier decrease with an increase of the power transfer. The flow of current increases with the power transfer which results in an increase in the conduction and switching losses. However, the MPC algorithm shows the better efficiency than the VOC-based PWM control method for the entire 
range of power transfer.

\section{CONCLUSION}

The stability and performance of the model predictive controlled AFE rectifier has been investigated in this paper. This model predictive control (MPC) method is simple, intuitive, and generates a sinusoidal input current with a unity power factor. The stability analysis of this control method is performed with the discrete z-domain response and nonlinear model analysis. The result confirms that the model predictive control (MPC) system is stable with an infinite gain margin and a very fast dynamic response. In addition, the experimental results show that the AFE rectifier is operated with a unity power factor, an acceptable THD (4.0\%) level, and a very low DC voltage ripple. The MPC algorithm is simpler when compared to the VOC-based PWM technique since it uses only one PI regulator. Moreover, the MPC algorithm generates an optimum switching signal that accurately tracks the reference value in every sapling time $\left(T_{\mathrm{s}}\right)$. Hence, the efficiency of the MPC controlled AFE rectifier has been increased by reducing the IGBT switching losses and by the elimination of reactive power. The results of the investigation using the model predictive algorithm are very encouraging for improving the performance of the active-front-end (AFE) rectifiers in energy storage systems, and they will open up new prospects in power electronics research.

\section{ACKNOWLEDGMENT}

The authors would like to thank the Ministry of Higher Education and University of Malaya for providing financial support through HIR-MOHE project UM.C/HIR/MOHE/ENG/24 and UMRG project No. RP006E-13ICT.

\section{REFERENCES}

[1] M. Bragard, N. Soltau, S. Thomas, and R. W. De Doncker, "The balance of renewable sources and user demands in grids: Power electronics for modular battery energy storage systems," IEEE Trans. Power Electron., Vol. 25, No. 12, pp. 3049-3056, Dec. 2010.

[2] J. M. Carrasco, L. G. Franquelo, J. T. Bialasiewicz, E. Galván, R. C. P. Guisado, M. A. Prats, J. I. Leon, N. Moreno-Alfonso, "Power-electronic systems for the grid integration of renewable energy sources: A survey," IEEE Trans. Ind. Electron., Vol. 53, No. 4, pp. 1002-1016, Aug. 2006.

[3] S. Vazquez, S. M. Lukic, E. Galvan, L. G. Franquelo, and J. M. Carrasco, "Energy storage systems for transport and grid applications," IEEE Trans. Ind. Electron., Vol. 57, No. 12, pp. 3881-3895, Dec. 2010.

[4] N. M. Tan, T. Abe, and H. Akagi, "Topology and application of bidirectional isolated dc-dc converters," in Proc. ICPE \& ECCE, pp. 1039-1046, 2011.

[5] J. R. Rodríguez, L. Dixon, J. R. Espinoza, J. Pontt, and P. Lezana, "PWM regenerative rectifiers: state of the art,"
IEEE Trans. Ind. Electron., Vol. 52, No. 1, pp. 5-22, Feb. 2005.

[6] A. Alias, N. A. Rahim, and M. A. Hussain, "Bidirectional three phase power converter," in Proc. Clean Energy and Tech. (CET), pp. 337-341, 2011.

[7] B. Singh, S. Gairola, B. N. Singh, A. Chandra, and K. Al-Haddad, "Multipulse AC-DC converters for improving power quality: a review," IEEE Trans. Power Electron., Vol. 23, No. 1, pp. 260-281, Jan. 2008.

[8] B. Singh, B. N. Singh, A. Chandra, K. Al-Haddad, A. Pandey, and D. P. Kothari, "A review of three-phase improved power quality AC-DC converters," IEEE Trans. Ind. Electron., Vol. 51, No. 3, pp. 641-660, Jun. 2004.

[9] J. Dannehl, C. Wessels, and F. W. Fuchs, "Limitations of voltage-oriented PI current control of grid-connected PWM rectifiers with LCL filters," IEEE Trans. Ind. Electron., Vol. 56, No. 2, pp. 380-388, Feb. 2009.

[10] P. Verdelho and G. Marques, "DC voltage control and stability analysis of PWM-voltage-type reversible rectifiers," IEEE Trans. Ind. Electron., Vol. 45, No. 2, pp. 263-273, Apr. 1998.

[11] M. Malinowski, M. P. Kazmierkowski, and A. M. Trzynadlowski, "A comparative study of control techniques for PWM rectifiers in AC adjustable speed drives," IEEE Trans. Power Electron., Vol. 18, No. 6, pp. 1390-1396, Nov. 2003.

[12] T. Noguchi, H. Tomiki, S. Kondo, and I. Takahashi, "Direct power control of PWM converter without power-source voltage sensors," IEEE Trans. Ind. Application, Vol. 34, No. 3, pp. 473-479, May/Jun. 1998.

[13] D. Zhi, L. Xu, and B. W. Williams, "Improved direct power control of grid-connected DC/AC converters," IEEE Trans. Power Electron., Vol. 24, No. 5, pp. 1280-1292, May 2009.

[14] C. Lascu, I. Boldea, and F. Blaabjerg, "A modified direct torque control for induction motor sensorless drive," IEEE Trans. Ind. Application, Vol. 36, No. 1, pp. 122-130, Jan./Feb. 2000.

[15] I. Takahashi and Y. Ohmori, "High-performance direct torque control of an induction motor," IEEE Trans. Ind. Application, Vol. 25, No. 2, pp. 257-264, Mar./Apr. 1989.

[16] C. Reza, M. D. Islam, and S. Mekhilef, "Modeling and experimental verification of ANN based online stator resistance estimation in DTC-IM drive," Journal of Electrical Engineering \& Technology, Vol. 9, No. 2, pp. 550-558, Jan. 2014.

[17] S. Vazquez, J. A. Sanchez, J. M. Carrasco, J. I. Leon, and E. Galvan, "A model-based direct power control for three-phase power converters," IEEE Trans. Ind. Electron., Vol. 55, No. 4, pp. 1647-1657, Apr. 2008.

[18] D. Zhi, L. Xu, B. W. Williams, L. Yao, and M. Bazargan, "A new direct power control strategy for grid connected voltage source converters," in Proc. ICEMS., pp. 1157-1162, 2008 .

[19] A. Bouafia, F. Krim, and J.-P. Gaubert, "Fuzzy-logic-based switching state selection for direct power control of three-phase PWM rectifier," IEEE Trans. Ind. Application, Vol. 56, No. 6, pp. 1984-1992, Jun. 2009.

[20] C. Reza, D. Islam, and S. Mekhilef, "Stator resistance estimation scheme using fuzzy logic system for direct torque controlled induction motor drive," Journal of Intelligent and Fuzzy Systems, to be published.

[21] J. Hu, L. Shang, Y. He, and Z. Zhu, "Direct active and reactive power regulation of grid-connected DC/AC converters using sliding mode control approach," IEEE Trans. Power Electron., Vol. 26, No. 1, pp. 210-222, Jan. 2011.

[22] P. Cortés, M. P. Kazmierkowski, R. M. Kennel, D. E. Quevedo, and J. Rodríguez, "Predictive control in power 
electronics and drives," IEEE Trans. Ind. Appl., Vol. 55, No. 12, pp. 4312-4324, Dec. 2008.

[23] J. Rodriguez, M. Kazmierkowski, J. Espinoza, P. Zanchetta, H. Abu-Rub, H. A. Young, and C. A. Rojas, "State of the art of finite control set model predictive control in power electronics," IEEE Trans. Power Electron., Vol. 9, No. 2, pp. 1003-1016, May 2013.

[24] M. Parvez, S. Mekhilef, N. M. Tan, and H. Akagi, "Model predictive control of a bidirectional AC-DC converter for V2G and G2V applications in electric vehicle battery charger," in Proc. ITEC, pp. 1-6, 2014.

[25] P. Cortés, J. Rodríguez, P. Antoniewicz, and M. Kazmierkowski, "Direct power control of an AFE using predictive control," IEEE Trans. Power Electron., Vol. 23, No. 5, pp. 2516-2523, Sep. 2008.

[26] S. Kouro, P. Cortés, R. Vargas, U. Ammann, and J. Rodríguez, "Model predictive control - A simple and powerful method to control power converters," IEEE Trans. Ind. Appl., Vol. 56, No. 6, pp. 1826-1838, Jun. 2009.

[27]S. Muslem Uddin, S. Mekhilef, M. Rivera, and J. Rodriguez, "A FCS-MPC of an induction motor fed by indirect matrix converter with unity power factor control," in Proc. ICIEA, pp. 1769-1774, 2013.

[28] M. Uddin, S. Mekhilef, M. Mubin, M. Rivera, and J. Rodriguez, "Model predictive torque ripple reduction with weighting factor optimization fed by an indirect matrix converter," Electric Power Components and Systems, Vol. 42, No. 10, pp. 1059-1069, Jun. 2014.

[29] M. Uddin, S. Mekhilef, M. Rivera, and J. Rodriguez, "Predictive indirect matrix converter fed torque ripple minimization with weighting factor optimization," in Proc. IPEC-Hiroshima 2014-ECCE-ASIA, pp. 3574-3581, 2014.

[30] R. P. Aguilera and D. E. Quevedo, "On stability and performance of finite control set MPC for power converters," in Workshop on Pred. Control of Elect. Drives and Power Electron. (PRECEDE), pp. 55-62, 2011.

[31] D. E. Quevedo, G. C. Goodwin, and J. A. De Dona, "Finite constraint set receding horizon quadratic control," Int. J. of Robust and Nonlinear Control, Vol. 14, No. 4, pp. 355-377, Mar. 2004.

[32] C. Xia, M. Wang, Z. Song, and T. Liu, "Robust model predictive current control of three-phase voltage source PWM rectifier with online disturbance observation," IEEE Trans. Ind. Informat., Vol. 8, No. 3, pp. 459-471, Aug. 2012.

[33] S. Muslem Uddin, P. Akter, S. Mekhilef, M. Mubin, M. Rivera, and J. Rodriguez, "Model predictive control of an active front end rectifier with unity displacement factor," in Proc. ICCAS, pp. 81-85, 2013.

[34] H.-S. Kim, K.-H. Kim, and M.-J. Youn, "On-line dead-time compensation method based on time delay control," IEEE Trans. Contr. Syst. Technol., Vol. 11, No. 2, pp. 279-285, Mar. 2003.

[35] H.-S. Kim, H.-T. Moon, and M.-J. Youn, "On-line dead-time compensation method using disturbance observer," IEEE Trans. Power Electron., Vol. 18, No. 6, pp. 1336-1345, Nov. 2003.

[36] H.-T. Moon, H.-S. Kim, and M.-J. Youn, "A discrete-time predictive current control for PMSM," IEEE Trans. Power Electron., Vol. 18, No. 1, pp. 464-472, Jan. 2003.

[37] M. H. Bierhoff and F. W. Fuchs, "Active damping for three-phase PWM rectifiers with high-order line-side filters,' IEEE Trans. Ind. Electron., Vol. 56, No. 2, pp. 371-379, Feb. 2009.

[38] B. Terzić, G. Majić, and A. Slutej, "Stability analysis of three-phase PWM converter with LCL filter by means of nonlinear model," Automatika, Vol. 51, No. 3, pp. 221-232, Sep. 2010.

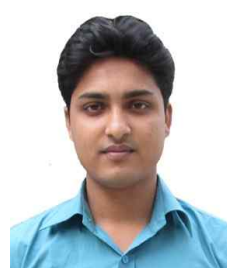

Md. Parvez Akter was born in Pabna, Bangladesh. He received his B.Sc. degree from the Chittagong University of Engineering and Technology (CUET), Chittagong, Bangladesh, in 2011. In 2011, he joined the Research and Development department of the HAMKO Corporation Ltd, Bangladesh as an Executive Engineer. He is currently pursuing his M.Eng Sc degree and working as a Research Assistant with the Power Electronics and Renewable Energy Research Laboratory (PEARL), Department of Electrical Engineering, University of Malaya, Kuala Lumpur, Malaysia. His current research interest is on power converters and electrical drives, bidirectional power conversion techniques, predictive and digital control, renewable energy, and wireless power transfer.

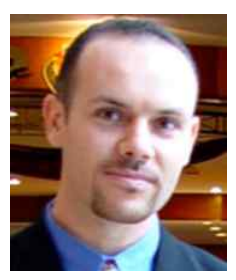

Saad Mekhilef received the B.Eng. degree in Electrical Engineering from the University of Setif, Setif, Algeria, in 1995, and the Master of Engineering Science and $\mathrm{Ph} . \mathrm{D}$. degrees from the University of Malaya, Kuala Lumpur, Malaysia, in 1998 and 2003, respectively. He is currently a Professor at the Department of Electrical Engineering, University of Malaya, Kuala Lumpur. He is the author or coauthor of more than 250 publications in international journals and proceedings. He is a Senior Member of the IEEE. He is actively involved in industrial consultancy, for major corporations in the power electronics projects. His current research interests include power conversion techniques, the control of power converters, renewable energy, and energy efficiency.

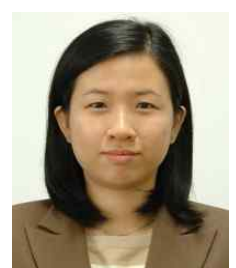

Nadia Mei Lin Tan was born in Kuala Lumpur, Malaysia. She received her B.Eng. (Hons.) degree from the University of Sheffield, Sheffield, U.K., in 2002, her M. Eng. degree from the Universiti Tenaga Nasional, Kajang, Malaysia, in 2007, and her Ph.D. degree from the Tokyo Institute of Technology, Tokyo, Japan, in 2010, all in Electrical Engineering. Since October 2010, she has been a Senior Lecturer in the Department of Electrical Power Engineering, Universiti Tenaga Nasional. Her current research interests include power conversion systems and bidirectional isolated dc-dc converters. Dr. Tan is a Graduate Member of the Institution of Engineers Malaysia (IEM) and a Member of the Institution of Engineering and Technology (IET).

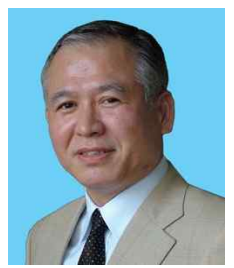

Hirofumi Akagi was born in Okayama, Japan, in 1951. He received his B.S. degree from the Nagoya Institute of Technology, Nagoya, Japan, in 1974, and his M.S. and Ph.D. degrees from the Tokyo Institute of Technology, Tokyo, Japan, in 1976 and 1979, respectively, all in Electrical Engineering. In 1979, he was with the Nagaoka University of Technology, Nagaoka, Japan, as an Assistant and then as an Associate Professor in the Department of Electrical Engineering. In 1987, he was a Visiting Scientist at the Massachusetts Institute of Technology, Cambridge, MA, USA. From 1991 to 1999, he was a Professor in the Department of Electrical Engineering, Okayama University, Okayama, Japan. From March to August of 1996, he was a Visiting Professor at the University of Wisconsin, Madison, WI, USA, and then at the 
Massachusetts Institute of Technology. Since January 2000, he has been a Professor in the Department of Electrical and Electronic Engineering, Tokyo Institute of Technology. His current research interests include power conversion systems, ac motor drives, active and passive EMI filters, high-frequency resonant inverters for induction heating and corona discharge treatment processes, and utility applications for power electronics such as active filters for power conditioning, self-commutated BTB systems, and FACTS devices. He has authored or coauthored more than 80 IEEE Transactions papers, and two invited papers in the Proceedings of the IEEE. According to Google Scholar, the total citation index for all his papers is more than 6,000 . He has made international presentations many times as a keynote speaker or as an invited speaker. Since January 2007, he has been the President of the IEEE Power Electronics Society (PELS). He was elected as a Distinguished Lecturer of the IEEE Industry Applications Society (IAS) and PELS for 1998-1999. He received two IEEE IAS Transactions Prize Paper Awards in 1991 and 2004, and two IEEE PELS Transactions Prize Paper Awards in 1999 and 2003. $\mathrm{He}$ has also received nine IEEE IAS Committee Prize Paper Awards, the 2001 IEEE William E. Newell Power Electronics Award, the 2004 IEEE IAS Outstanding Achievement Award, and the 2008 IEEE Richard H. Kaufmann Technical Field Award. 